\title{
Perceptions and risk factors for lameness on organic and small conventional dairy farms
}

\author{
R. M. Richert, ${ }^{\star}$ K. M. Cicconi, $†$ M. J. Gamroth, $\ddagger$ Y. H. Schukken, $†$ K. E. Stiglbauer, $\ddagger$ and P. L. Ruegg ${ }^{* 1}$ \\ *Department of Dairy Science, University of Wisconsin, Madison 53706 \\ †Quality Milk Production Services, Cornell University, Ithaca, NY 14850 \\ ‡Department of Animal Sciences, Oregon State University, Corvallis 97331
}

\section{ABSTRACT}

Lameness is an important multifactorial disease that affects dairy cattle on both organic (ORG) and conventional (CON) farms. The objective of this study was to characterize perception of lameness and identify risk factors for lameness prevalence on ORG and similarlysized CON farms. Dairy herds $(\mathrm{n}=292)$ were enrolled across 3 states (NY, OR, WI), with CON herds enrolled based on similar herd size and location of ORG herds. During a single herd visit, information was collected about management practices and lameness events occurring in the previous $60 \mathrm{~d}$, and paperwork was left to record lameness events during the $60 \mathrm{~d}$ after the visit. During the herd visit, study personnel scored cows for body condition, lameness, and hock condition. For analysis, CON herds were further divided into CON grazing and CON nongrazing. A Poisson regression model was used to assess risk factors for prevalence of cows scored lame. On these relatively small, lower producing farms, the prevalence of lameness in cows scored by study personnel was less than previously reported for larger, higher producing dairy herds located in the United States. Prevalence of lameness was weakly and positively correlated with the rate of lameness calculated using farmer records. Researchers observed lame cows on some farms where farmers perceived that lameness never occurred. An increased prevalence of cows scored lame by study personnel was associated with an increased prevalence of hock lesions, use of CON nongrazing management, and routine use of a footbath. Multiple strategies may be used to manage lameness on farms, including increasing farmer perception of lameness and reduction in exposure of cows to risk factors that contribute to development of lameness.

Key words: organic management, lameness, disease, dairy management

Received October 11, 2012.

Accepted May 7, 2013.

${ }^{1}$ Corresponding author: plruegg@wisc.edu

\section{INTRODUCTION}

Lameness is a common condition of dairy cattle that negatively affects the well-being of animals in both organic (ORG) and conventional (CON) management systems (Marley et al., 2010). Management factors that have been associated with the prevalence of lameness include the type and depth of bedding materials (Rouha-Mülleder et al., 2009), housing type (Regula et al., 2004), and feeding a grazing-based diet (Haskell et al., 2006). These management factors have also been shown to differ between ORG and CON dairy farms in the United States (Zwald et al., 2004; Sato et al., 2005; Pol and Ruegg, 2007), and therefore may confound the potential effect of ORG management on incidence of lameness.

Several researchers have compared risk factors for lameness on ORG and CON dairy farms in Europe (Dippel et al., 2009a; Rutherford et al., 2009; Barker et al., 2010), but no studies of this sort have been reported for US dairy herds, and national standards for managing ORG dairy farms are different in the United States compared with other regions (Ruegg, 2009). Dippel et al. (2009a) included ORG and CON herds from separate geographic regions and with differing breeds and pasture access, thereby possibly confounding the potential effect of management system. Rutherford et al. (2009) suggested that prevalence of lameness may be decreased for cattle on ORG farms, but did not compare risk factors between the management systems. In a larger study including ORG $(\mathrm{n}=67)$ and CON ( $\mathrm{n}=137)$ herds, type of management system was not associated with prevalence of lameness (Barker et al., 2010). To date, insufficient evidence has been reported to conclude if rates of lameness or risk factors for lameness vary between management systems used in the United States.

The farmer-identified incidence of lameness in dairy cows may be associated with the farmer's knowledge of and perceptions of lameness. In one report, knowledge and training regarding lameness were inversely correlated with incidence of lameness (Mill and Ward, 1994). Several previous researchers suggest that farmers tend 
to underestimate the amount of lameness (Wells et al., 1993; Rutherford et al., 2009; Leach et al., 2010), and the prevalence of lameness reported by farmers has been shown to correlate poorly with prevalence measured by researchers (Whay et al., 2003). Farmers who underestimate lameness may not consider it as an important issue, and therefore may be less likely to implement control programs (Leach et al., 2010). The objective of this study was to identify perceptions of lameness by dairy farmers and risk factors for lameness in dairy cows on organic and similarly sized conventional grazing and nongrazing dairy farms.

\section{MATERIALS AND METHODS}

\section{Data Collection}

Information about herd recruitment and data collection has been previously described (Richert et al., accepted; Stiglbauer et al., 2013). In brief, farms ( $\mathrm{n}=$ 292) were recruited between April 2009 and April 2011 from dairy herds located in New York, Oregon, and Wisconsin. All herds were required to have a minimum of 20 cows and must have been shipping milk for at least 2 yr. Organic herds must have been shipping certified ORG milk for at least $2 \mathrm{yr}$. Conventional herds were enrolled based on similar location and herd size of enrolled ORG herds. During a single farm visit, a questionnaire on management practices (including farmers' perceptions of occurrence of lameness) was administered (available at http://milkquality.wisc.edu/ organic-dairies/project-c-o-w). Information was collected about occurrence of lameness and culling during the $60 \mathrm{~d}$ before the farm visit (retrospective period). Prospective data was collected for the 60 -d period after the farm visit using defined recording forms. Farmers were instructed to recall or record information about all lame animals, regardless of administration of treatment, and all animals that left the herd for any reason. Study approval was obtained from the Institutional Review Board and Animal Care and Use Committee at Oregon State University. In each state, a single member of the study team conducted all interviews. Before herd visits began, all study personnel met and were trained on administration of the survey instrument and scoring systems used in the study. Throughout the data collection period, monthly conference calls were held to discuss questions and ensure standardization of data collection among states.

During the farm visit, study personnel assessed BCS (Ferguson et al., 1994), hock condition, and lameness. Scores were obtained from all lactating cows (up to 50 ), or for larger herds, a randomly selected, representative sample of $20 \%$ of lactating cows was scored.
Hock condition was scored using an adapted 3-point scoring system based on Fulwider et al. (2007) with the 2 most severe categories of lesions combined. Hocks were scored as (1) normal (no hair loss or swelling), (2) hair loss and no swelling (including small scabs), or (3) moderate or severe swelling or visible wounds. Lameness was scored by adapting the 5-point scale of Sprecher et al. (1997) into dichotomous categories of lame or not lame. Cows that stood with a level-back posture and had a normal gait were scored as not lame (scored as 1 or 2 according to Sprecher et al., 1997), whereas cows that had an arched-back posture both while standing and walking and had an abnormal gait were scored as lame (scored as 3, 4, or 5 according to Sprecher et al., 1997). On many farms, scores were performed while observing cows on pasture. However, 78 farms used tiestalls, and in Wisconsin and New York some cows that were tied in stall barns were scored based only on observations while they were standing in the barn. In most instances, cows that were restrained were considered lame when they were observed standing with an arched-back posture. Scoring while the cow was restrained occurred only when stabled animals were not being released during the farm visits. In most instances, lameness scores of stabled cows were verified by observation of the cows as they walked out of the barn.

\section{Definitions of Variables}

Prevalence of lameness was defined as the percent of cows scored as lame by study personnel during the herd visit, and was recorded on all farms. Rate of farmeridentified lameness events was measured per cow-year at risk. Lameness events were identified and recorded by farmers during either the retrospective or combined (retrospective and prospective) data collection period. Cow-years at risk for lameness were calculated for each herd by multiplying the number of lactating and dry cows at the time of the herd visit by $60 \mathrm{~d}$ if data was available for only the retrospective data collection period or $120 \mathrm{~d}$ if data was available for the combined data collection period, then dividing by $365 \mathrm{~d}$.

Management system (ORG, CON) and use of grazing ( $\geq 30 \%$ of DMI for lactating cows was obtained from pasture during the grazing season; yes, no) were combined to create a new 3 -level variable (grazing system): (1) ORG, (2) CON grazing (CON-GR), and (3) CON nongrazing (CON-NG). Grazing system, site (NY, OR, WI), and herd size category (20-99, 100-199, and $\geq 200$ lactating and dry cows) were associated with the design of the study and were forced into both models. Selected risk factors considered for the multivariable model were rolling herd average (RHA), amount of 
grain fed, proportion of lactating and dry cows in first lactation, prevalence of cows with hock lesions (score 2 or 3 ), proportion of cows with BCS $<2.5$, proportion of cows culled for beef during the data collection period, farmer-reported lameness as 1 of the 3 primary symptoms used to screen for ill cows (yes, no), use of bull breeding (some or all, AI exclusive), use of a nutritionist (yes, no), use of a TMR (yes, no), use of written herd health records (yes, no), predominant breed $(>50 \%$ of cows; Holstein, Jersey, other), primary housing for lactating cows (freestall, group pen, pasture or drylot, stall barn), season of visit (spring, summer, autumn, winter), average hours spent outside in the $60 \mathrm{~d}$ before herd visit (none, 1-8, 9-19, 20-24), rate of routinely scheduled veterinary visits per 100 cows per year (none, few, some, many), likelihood of farmer to call a veterinarian for an off-feed cow (low, medium, high), routine use of a footbath (yes, no), routinely performing hoof trimming (yes, no), use of improved laneways (yes, no), number of years operating a dairy farm, and number of days per year that cows graze.

\section{Statistical Procedures}

The herd was the unit of analysis. Descriptive statistics were used to verify data accuracy, detect missing data, and observe frequency distributions. Statistical significance was defined as $P \leq 0.05$ for all analyses. Data were tested for presence of selection bias for completion of the data collection period. Wilcoxon ranksum tests were performed using PROC NPAR1WAY (SAS Institute, 2011) to determine if herd size and RHA were independent of completion of prospective data forms. Chi-squared analyses were performed using PROC FREQ (SAS Institute, 2011) to determine if site was independent of completion of prospective data forms. A Cochran-Mantel-Haenszel analysis was performed to determine if grazing system was independent of completion of prospective data forms after adjustment for differences in recruitment by site (Richert et al., 2013).

The PROC NPAR1WAY (SAS Institute, 2011) was used to perform Wilcoxon rank-sum tests to determine if rate of farmer-identified lameness events, prevalence of cows scored lame, and prevalence of hock lesions were independent of grazing system. The PROC CORR (SAS Institute, 2011) was used to assess Spearman's rank correlation coefficients between the prevalence of cows scored lame and rate of farmer-identified lameness events. The Kolmogorov-Smirnov test of composite normality was used to assess the normality of the prevalence of cows scored lame, which was found to deviate from normality $(P=0.010)$, and therefore was modeled using Poisson regression. The Poisson regres- sion model was performed using the PROC GENMOD (SAS Institute, 2011) to determine associations between selected explanatory variables and prevalence of cows scored lame. A scale parameter, estimated by deviance divided by degrees of freedom, was used to adjust for overdispersion.

The general form of the linearized model was

$$
f(\text { prevalence })=\alpha+\beta_{i} \text { risk } \text { factor }_{i}+e,
$$

where $f$ (prevalence) is the log-link of the percentage of cows scored lame per herd; $\alpha$ is the intercept; $\beta_{i}$ is the regression coefficient for selected risk factor ${ }_{i}$; and $e$ is the Poisson-distributed random error. Estimated regression coefficients of the model were expressed exponentially and interpreted as a relative rate ratio (Dohoo et al., 2003).

Model selection was performed by first screening for unconditional associations between each selected explanatory variable and the outcome variable. All design variables (grazing system, site, and herd size) and risk factors unconditionally associated with prevalence of cows scored lame at $P \leq 0.20$ were offered for multivariable modeling. One multivariable Poisson regression model was constructed using backward and forward variable selection procedures. The final model consisted of risk factors significant at $P \leq 0.05$ and all design variables. No variables resulted in substantial ( $\geq 20 \%$; Dohoo et al., 2003) changes among rate ratios of other explanatory variables, indicating that confounding was not a problem.

\section{RESULTS}

Retrospective information about sick cows was collected on 95 New York, 40 Oregon, and 147 Wisconsin farms, and prospective information about sick cows was returned by $29(30 \%)$ of the New York, $31(78 \%)$ of the Oregon, and 118 (80\%) of the Wisconsin farmers, for a total of 178 farmers completing the combined data collection period for sick cows (Richert et al., 2013). Herd size and RHA were not associated with completion of the data collection period. After adjusting for state, grazing system was not associated with completion of the data collection period for sick cows $(P=0.124)$.

Data included in the rate of farmer-identified lameness events was from farmers who returned data for either the retrospective or combined data collection periods $(\mathrm{n}=187$ ORG, $\mathrm{n}=34 \mathrm{CON}-\mathrm{GR}, \mathrm{n}=61 \mathrm{CON}$ NG). Of these farmers, $143(51 \%)$ did not identify any lameness events during the data collection period for their farm. The overall rate of lameness events identified by farmers ranged from 0 to 0.89 cases/cow-year, and tended to be greater in CON-NG herds as com- 
pared with ORG and CON-GR $(P=0.071$; Figure 1$)$. The overall prevalence of lameness as scored by study personnel ranged from 0 to $54 \%$ (mean $8 \%$ ) of scored cows and did not differ among grazing systems $(P=$ 0.134 ; Figure 2). Rate of lameness events identified by farmers and prevalence of cows scored as lame by study personnel had a Spearman's rank correlation coefficient of $0.152(P=0.010)$. Of farmers who returned data, 25 $(9 \%)$ reported during the interview that they did not perceive lameness to ever occur on their farms. Of these farmers, 11 (ORG), 6 (CON-GR), and 5\% (CON-NG), did not perceive lameness to ever occur on their farms $(P=0.313)$. Of farmers who did not perceive lameness to ever occur on their farms, $1(4 \%)$ identified lameness during the data collection period and $15(60 \%)$ had cows that were scored as lame by study personnel. The median proportion of the herd scored as lame was $6 \%$ for farmers who did perceive lameness to occur on their farms, in contrast to $4 \%$ for farmers who did not perceive lameness to ever occur on their farms $(P=0.082)$.

Explanatory variables unconditionally associated with an increase in the prevalence of cows scored lame $(P \leq 0.20)$ are described in Table 1 . Of the explanatory variables unconditionally associated with the prevalence of lameness scored by study personnel, the variables that remained in the final multivariable model were site, prevalence of cows with $\mathrm{BCS}<2.5$, prevalence of hock lesions, average hours cows spent outdoors in the $60 \mathrm{~d}$ before the herd visit, routine use of a footbath, grazing system, likelihood for the farmer to call a veterinarian for an off-feed cow, and rate of routinely scheduled veterinary visits (Table 2).

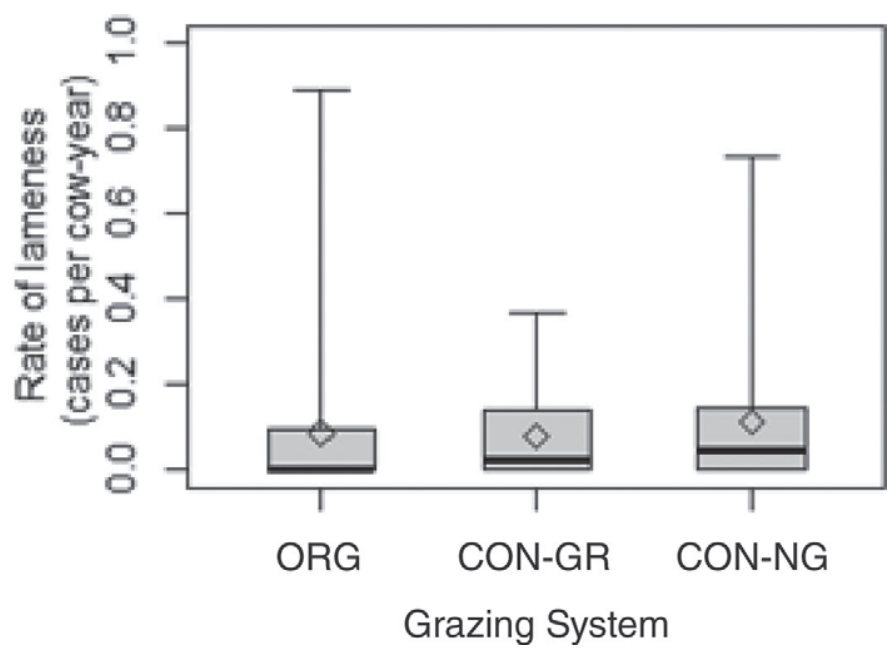

Figure 1. Rate of farmer-identified lameness events (cases/cowyear) by grazing system for data collected from 187 organic (ORG), 34 conventional grazing (CON-GR), and 61 conventional nongrazing (CON-NG) herds located in New York, Oregon, and Wisconsin. Rate of lameness tended to differ among grazing systems $(P=0.071)$.

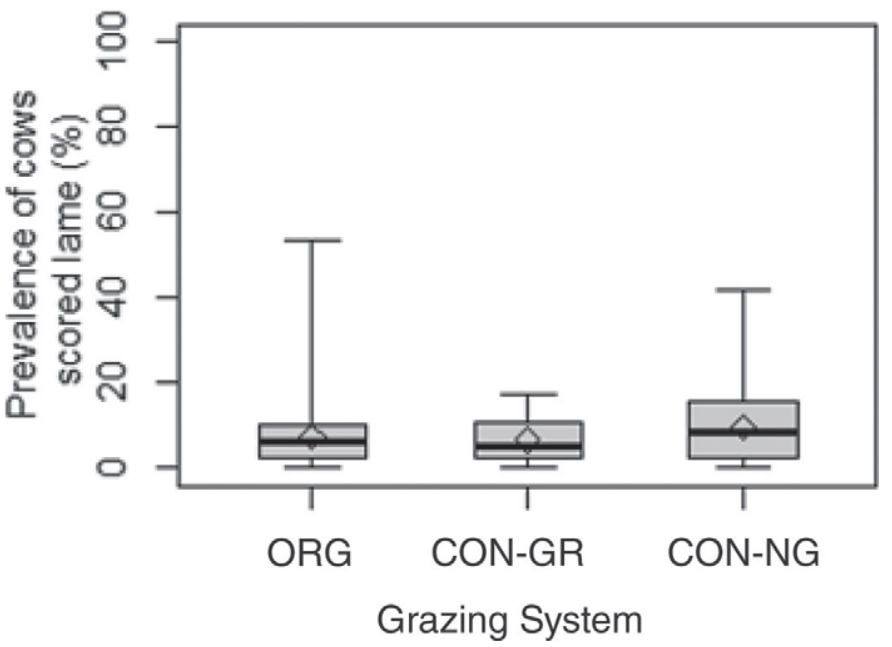

Figure 2. Prevalence of cows scored as lame by study personnel by grazing system for data collected from 192 organic (ORG), 36 conventional grazing (CON-GR), and 64 conventional nongrazing (CON-NG) herds located in New York, Oregon, and Wisconsin. Prevalence of cows scored as lame did not differ among grazing systems $(P=0.134)$.

An increased prevalence of hock lesions and cows with BCS $<2.5$ were associated with an increased prevalence of lameness scored by study personnel. Herds located in New York had approximately twice the prevalence of cows scored lame as compared with herds located in Oregon and Wisconsin. Prevalence of cows scored lame was greatest on CON-NG as compared with CON-GR and ORG farms. The prevalence of cows scored lame was greatest in herds where the cows spent an average of 9 to $19 \mathrm{~h}$ outdoors in the $60 \mathrm{~d}$ before the herd visit. Farmers who reported a high or medium likelihood to call a veterinarian for an off-feed cow had an increased prevalence of cows scored lame in their herds as compared with farmers who reported a low likelihood to call a veterinarian for an off-feed cow. Herds that had few or many routine veterinary visits had a decreased prevalence of cows scored lame as compared with herds that had none or some routine veterinary visits. Farmers who routinely use a footbath had a greater prevalence of lameness in their herds as compared with farmers who did not routinely use a footbath.

\section{DISCUSSION}

The herds enrolled in this study represented small ORG and CON dairy farms located in 3 US states, and the reference population should be considered to be relatively small herds that use similar management strategies. Characteristics of the herds have been previously described (Richert et al., 2013; Stiglbauer et al., 2013). In general, the herds were relatively small, $(72 \%$ contained $<100$ cows), lower producing (average milk 
Table 1. Unadjusted estimates and mean prevalence of lameness as scored by study personnel for all explanatory variables that were individually associated with prevalence of cows scored lame in herds located in New York, Oregon, and Wisconsin

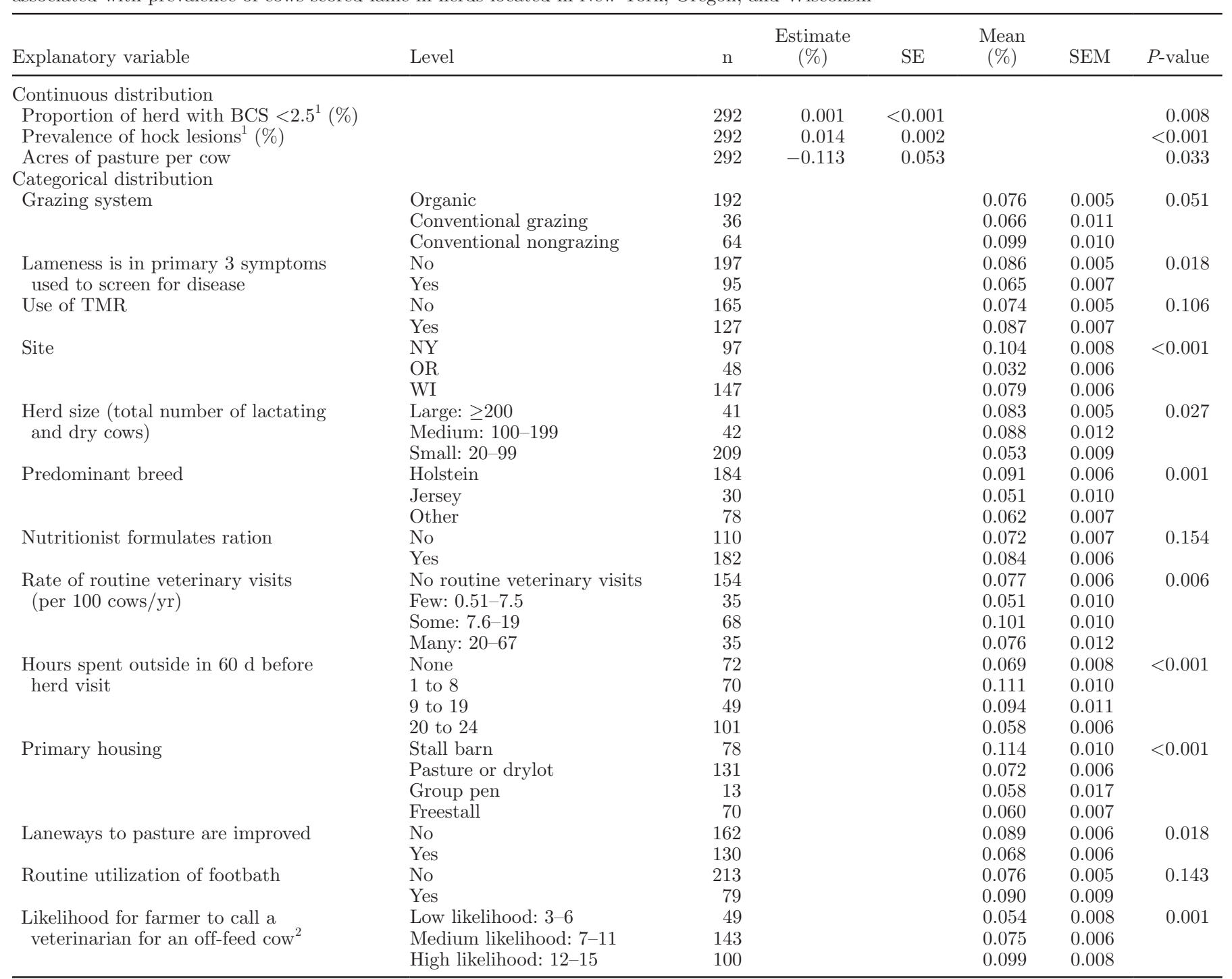

${ }^{1}$ Scored by study personnel during the herd visit.

${ }^{2}$ The farmer-reported likelihood to call a veterinarian for an off-feed cow in 3 scenarios were summed, creating a likelihood scale ranging from 3 to 15 .

yield was $27.9 \mathrm{~kg} /$ cow per day), and were composed of a more diverse breed distribution (predominant breeds were $63 \%$ Holstein, 10\% Jersey, and 27\% crossbred) as compared with herds previously used in studies of lameness in the United States (Cook, 2003; Espejo and Endres, 2007). The rates of lameness events identified by farmers ranged from 0 to 0.89 cases/cow-year and were comparable to rates collected from herd records of 53 similarly sized UK dairy farms (Whay et al., 2003).

The prevalence of lameness in cows scored by study personnel ranged from 0 to $54 \%$, and was similar to the range of 7.9 to $51.9 \%$ previously reported for 30 Wisconsin herds (Cook, 2003). However, in the current study, the mean prevalence of cows scored lame was $8 \%$ (median 6\%), as compared with a mean prevalence of 21 to $24 \%$ previously reported by Cook (2003). The greater prevalence reported by Cook (2003) is unlikely to be a result of differences in herd size, as the mean size of the herds (120 cows) was only slightly larger than herds enrolled in the current study. However, only $63 \%$ of the herds in the current study contained Holsteins as the predominant breed, and the rolling herd average milk production was almost $3,000 \mathrm{~kg} / \mathrm{cow}$ per year less than that reported by Cook (2003). Protocols used for scoring lameness varied between the 2 studies. In the current study, a simple scoring protocol was used that 
Table 2. Adjusted estimates of prevalence of lameness as scored by study personnel for all explanatory variables that remained in the final multivariable Poisson regression model of data from 292 herds located in New York, Oregon, and Wisconsin ${ }^{1}$

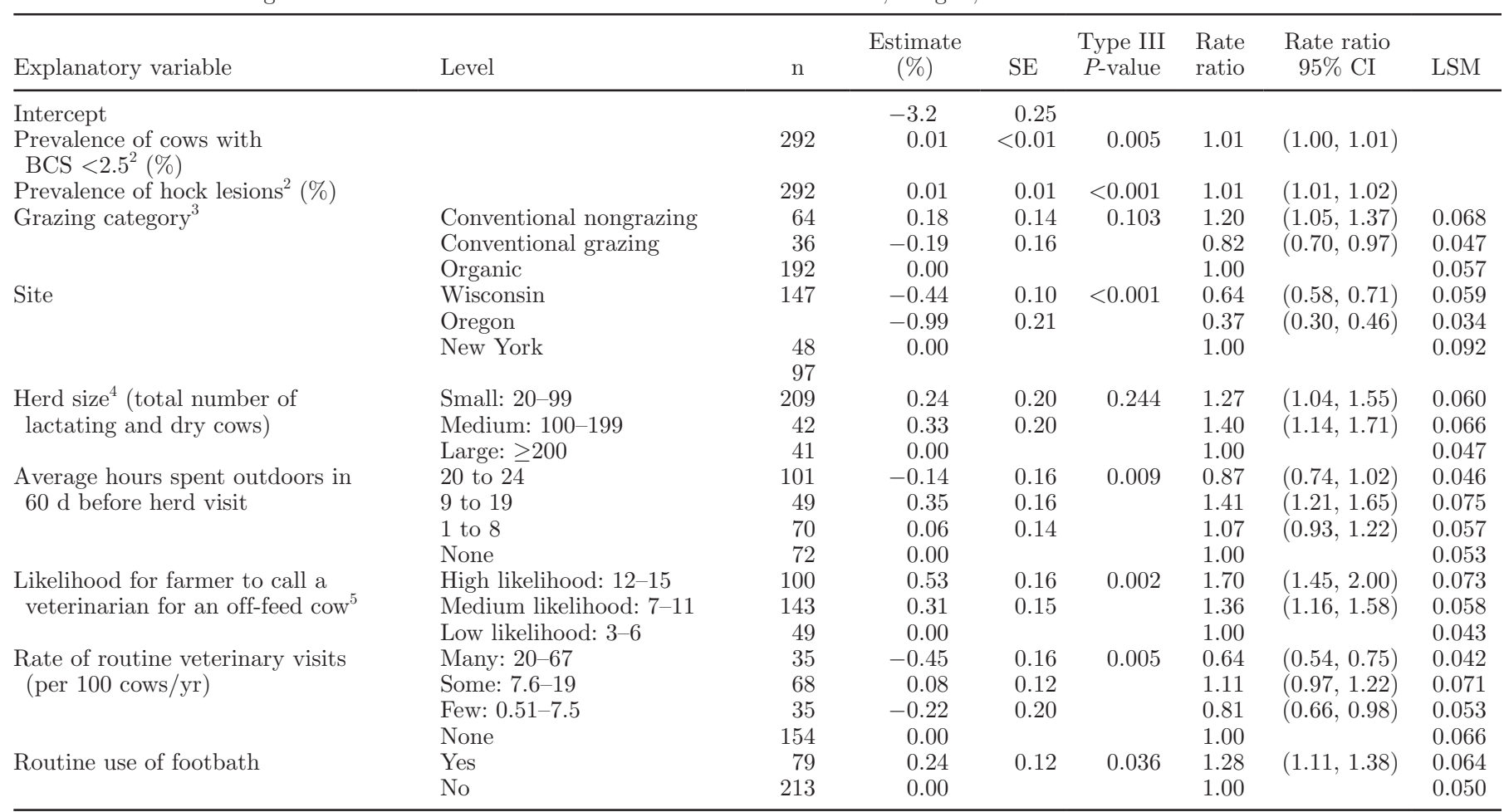

\footnotetext{
${ }^{1}$ The Akaike information criterion of the final multivariable model was 171, with a Pearson chi squared of 276 and 274 degrees of freedom.

${ }^{2}$ Scored by study personnel during herd visit.

${ }^{3}$ Grazing system was included in the design of the study, and therefore was forced into the final multivariable model.

${ }^{4}$ Herd size was included in the design of the study, and therefore was forced into the final multivariable model.

${ }^{5}$ The farmer-reported likelihood to call a veterinarian for an off-feed cow in 3 scenarios were summed, creating a likelihood scale ranging from 3 to 15 .
}

scored cows as either sound or lame based on standing or moving posture. For some cows that were tied in stall barns, study personnel scored cows based solely on posture (cows were not released individually from the stall to observe movement). In contrast, Cook (2003) used a more precise 4-point scoring system and released cows from their stalls and scored them while walking. Others have demonstrated that cows with mild signs of lameness are more likely to be misclassified as healthy when lameness is assessed while cows are tied (Leach et al., 2009). In the current study, the prevalence of cows scored as lame may have been underestimated by up to $25 \%$ for some herds that used stall barn housing; however, in many instances, the scores were verified by observing the cows as they were released from their stalls and left the barn, and thus it is likely that the differences observed are associated with other risk factors.

Large herd size was not significantly associated with decreased prevalence of lameness scores. Previous investigations of the association between herd size and lameness have led to contradictory outcomes. Alban (1995) reported that increased herd size was associated with decreased risk of lameness. However, the study design involved analysis of lameness at the cow level and risk factors at the herd level, which may cause ecologic fallacy when interpreting results. Other researchers have reported no association between herd size and prevalence or risk of lameness (Amory et al., 2006; Barker et al., 2010), or they have reported that increased herd size is associated with an increased rate of lameness (Groehn et al., 1992; Dippel et al., 2009b). Cows in larger herds may be at less risk for lameness if more resources have been invested in preventative management practices (Dippel et al., 2009b), such as improved housing, use of automatic manure removal, and improved and nonabrasive walking and lying surfaces (Barker et al., 2010).

The average number of hours cows spent outdoors in the $60 \mathrm{~d}$ before the herd visit remained in the final multivariate model. Herds that spent 9 to $19 \mathrm{~h}$ tended to have a greater prevalence of lameness as compared with other groups; however, no clear trend to this data was observed. This variable measured time that cows were outside irrespective of grazing. Some ORG and 
CON-GR herds were visited during seasons when they were not able to graze, but those animals may have gone outside for exercise. Additionally, many herds (including $\mathrm{CON}-\mathrm{NG}$ ) may have let cows spend time outside in an exercise yard, drylot, or pasture that did not meet the definition of grazing used in the study (>30\% DMI from pasture). This relationship should be explored in more detail in future studies.

In the multivariable model, routine use of a footbath was associated with a greater prevalence of cows scored as lame. This result agrees with previous studies performed in Europe (Amory et al., 2006; Barker et al., 2010). It is important to recognize that for this and other associations, the cross-sectional nature of the study precludes determination of the direction of association, so illogical results should be viewed cautiously. Use of footbaths may cause an increased prevalence of lameness if the footbath solution is at an inadequate concentration, contaminated, or not changed at an adequate frequency (Amory et al., 2006). Alternatively, if many lame cows are present on a farm, the farmer may be more likely to use a footbath (Amory et al., 2006; Barker et al., 2010). In a similar fashion, a greater proportion of cows with a low BCS may be associated with an increased prevalence of lameness if lame cows are less likely to get up to eat, thereby losing body condition, or thin cows may be predisposed to developing lameness.

The rate of farmer-identified lameness events is a measure of the farmer's ability to perceive lameness, whereas the prevalence of lameness was determined by study personnel using a standardized scoring system. Both incidence and duration affect prevalence, and a portion of the difference between these measures may be due to differences in duration of lameness or to differences between researchers and farm personnel in their definitions of lameness. Similar to Whay et al., (2003), the prevalence of lame cows scored by study personnel had a weak positive correlation with rate of lameness events identified by farmers. However, previous researchers have reported a positive association between the prevalence of lameness measured by researchers and the perception of lameness as a moderate or severe herd problem by farmers (Leach et al., 2010). Farmers who perceive lameness as problematic have been shown to be more likely to implement lameness control programs (Leach et al., 2010) and to proactively detect lameness (Barker et al., 2010).

Perceptions of lameness varied among farmers. Similar to previous reports that indicated that farmers underestimate lameness (Wells et al., 1993; Rutherford et al., 2009; Leach et al., 2010), study personnel observed lame cows on $60 \%$ of farms where farmers reported that they did not perceive lameness to ever occur. Study personnel scored cows as lame when the cows were observed standing with an arched-back posture or walking with short-strided gait. It is likely that most farmers used a less sensitive definition of lameness and detected only the more severe cases. Farmers have been reported to become habituated to lameness, and thus may perceive abnormal gaits as normal (Leach et al., 2010). Future extension programs should be directed toward increasing awareness of mildly lame cattle so that preventive management practices can be implemented before the disease progresses.

Prevalence of hock lesions as scored by study personnel ranged from 0 to $95 \%$ of cows per farm, with a mean of $19 \%$ (median of $12 \%$ ) of the cows demonstrating hock lesions. Previous researchers used similar hock scoring scales in 2 US studies of cattle housed in freestalls and reported that the mean prevalence of hock lesions were 23.5\% (Lombard et al., 2010) and 25, 35.2, and 71.6\% for sand, waterbed, and rubber-filled mattress freestall beds, respectively (Fulwider et al., 2007). The prevalence of hock lesions in cows included in the current study may be less because many cows were in herds that used loose housing or grazing, both of which are associated with decreased prevalence of hock and knee lesions (Haskell et al., 2006; Keil et al., 2006). In the final multivariable model, increased prevalence of hock lesions was positively associated with prevalence of cows scored lame. These results agree with previous reports of a positive association between hock lesions and risk of lameness (Haskell et al., 2006; Fulwider et al., 2007; Kielland et al., 2009). Similar housing factors may be risk factors for both lameness and hock lesions, explaining the association between lameness and hock lesions (Kielland et al., 2009).

A nonsignificant tendency was observed for prevalence of lameness to be decreased in herds that grazed in the final model. Previous researchers have suggested that grazing decreases lameness (Haskell et al., 2006; Olmos et al., 2009; Rutherford et al., 2009) and hoof lesions (Somers et al., 2003). The prevalence of lameness on ORG herds was intermediate between CON-GR and CON-NG herds. No pattern was apparent for use of ORG management to influence lameness prevalence, similar to the report by Barker et al., (2010).

The differences in lameness prevalence by site may be due to site-specific differences among herds that did not remain in the final model, such as differences in breed and primary housing. Herds in Oregon tended to have more Jersey cattle and be housed in freestalls, whereas herds in Wisconsin and New York were more likely to use stall barn housing. Although attempts were made through common training and frequent communication 
to standardize scoring between sites, a portion of the difference in prevalence among sites may also be due to differences in scoring between personnel at each site.

Risk factors for the prevalence of lameness included 2 variables associated with the use of veterinarians. The prevalence of lameness appeared to increase with a farmer's likelihood of calling a veterinarian for an offfeed cow, perhaps indicating that veterinary interaction to treat sick cows was more frequent on farms with an increased prevalence of lameness. In contrast, no clear trend was noted for the association between the routine use of veterinarians and prevalence of lameness; more research is needed to further define these associations.

\section{CONCLUSIONS}

The prevalence of lameness observed in this population was less than previously reported for larger, more intensively managed US dairy herds. Farmers tend to underestimate the amount of lameness occurring in cattle on their farms and may believe that lameness is not occurring even, whereas trained observers can detect visibly lame cows. When using farm records to assess risk factors for lameness, it is important to account for differences in perception among farmers. Management factors associated with an increased prevalence of cows scored lame included an increased prevalence of hock lesions, use of CON-NG management, and routine use of a footbath. It is necessary to increase farmer awareness of lameness as a problem as well as manage important risk factors that are associated with increased lameness. Research about lameness should be accompanied by proactive extension programs that help farmers to improve detection and prevention of lameness in dairy cattle.

\section{ACKNOWLEDGMENTS}

This study was funded by the USDA NIFA project 2008-51106-19463, "Impact of Organic Management on Dairy Animal Health and Well-being."

\section{REFERENCES}

Alban, L. 1995. Lameness in Danish dairy cows: Frequency and possible risk factors. Prev. Vet. Med. 22:213-225.

Amory, J. R., P. Kloosterman, Z. E. Barker, J. L. Wright, R. W. Blowey, and L. E. Green. 2006. Risk factors for reduced locomotion in dairy cattle on nineteen farms in the Netherlands. J. Dairy Sci. 89:1509-1515.

Barker, Z. E., K. A. Leach, H. R. Whay, N. J. Bell, and D. C. J. Main. 2010. Assessment of lameness prevalence and associated risk factors in dairy herds in England and Wales. J. Dairy Sci. 93:932-941.

Cook, N. B. 2003. Prevalence of lameness among dairy cattle in Wisconsin as a function of housing type and stall surface. J. Am. Vet. Med. Assoc. 223:1324-1328.
Dippel, S., M. Dolezal, C. Brenninkmeyer, J. Brinkmann, S. March, U. Knierim, and C. Winckler. 2009a. Risk factors for lameness in freestall-housed dairy cows across two breeds, farming systems, and countries. J. Dairy Sci. 92:5476-5486.

Dippel, S., M. Dolezal, C. Brenninkmeyer, J. Brinkmann, S. March, U. Knierim, and C. Winckler. 2009b. Risk factors for lameness in cubicle housed Austrian Simmental dairy cows. Prev. Vet. Med. 90:102-112.

Dohoo, I., W. Martin, and H. Stryhn. 2003. Veterinary Epidemiologic Research. AVC Inc., Charlottetown, Canada.

Espejo, L. A., and M. I. Endres. 2007. Herd-level risk factors for lameness in high-producing cows housed in freestall barns. J. Dairy Sci. 90:306-314.

Ferguson, J. D., D. T. Galligan, and N. Thomsen. 1994. Principal descriptors of body condition score in Holstein cows. J. Dairy Sci. 77:2695-2703.

Fulwider, W. K., T. Grandin, D. J. Garrick, T. E. Engle, W. D. Lamm, N. L. Dalsted, and B. E. Rollin. 2007. Influence of free-stall base on tarsal joint lesions and hygiene in dairy cows. J. Dairy Sci. 90:3559-3566

Groehn, J. A., J. B. Kaneene, and D. Foster. 1992. Risk factors associated with lameness in lactating dairy cattle in Michigan. Prev. Vet. Med. 14:77-85.

Haskell, M. J., L. J. Rennie, V. A. Bowell, M. J. Bell, and A. B. Lawrence. 2006. Housing system, milk production, and zero-grazing effects on lameness and leg injury in dairy cows. J. Dairy Sci. 89:4259-4266.

Keil, N. M., T. U. Wiederkehr, K. Friedli, and B. Wechsler. 2006. Effects of frequency and duration of outdoor exercise: On the prevalence of hock lesions in tied Swiss dairy cows. Prev. Vet. Med. $74: 142-153$.

Kielland, C., L. E. Ruud, A. J. Zanella, and O. Østerås. 2009. Prevalence and risk factors for skin lesions on legs of dairy cattle housed in freestalls in Norway. J. Dairy Sci. 92:5487-5496.

Leach, K. A., S. Dippel, J. Huber, S. March, C. Winckler, and H. R. Whay. 2009. Assessing lameness in cows kept in tie-stalls. J. Dairy Sci. 92:1567-1574

Leach, K. A., H. R. Whay, C. M. Maggs, Z. E. Barker, E. S. Paul, A. K. Bell, and D. C. J. Main. 2010. Working towards a reduction in cattle lameness: 1 . Understanding barriers to lameness control on dairy farms. Res. Vet. Sci. 89:311-317.

Lombard, J. E., C. B. Tucker, M. A. G. von Keyserlingk, C. A. Kopral, and D. M. Weary. 2010. Associations between cow hygiene, hock injuries, and free stall usage on US dairy farms. J. Dairy Sci. 93:4668-4676.

Marley, C. L., R. F. Weller, M. Neale, D. C. J. Main, S. Roderick, and R. Keatinge. 2010. Aligning health and welfare principles and practice in organic dairy systems: A review. Animal 4:259-271.

Mill, J. M., and W. R. Ward. 1994. Lameness in dairy cows and farmers' knowledge, training and awareness. Vet. Rec. 134:162-164.

Olmos, G., L. Boyle, A. Hanlon, J. Patton, J. J. Murphy, and J. F. Mee. 2009. Hoof disorders, locomotion ability and lying times of cubicle-housed compared to pasture-based dairy cows. Livest. Sci. 125:199-207.

Pol, M., and P. L. Ruegg. 2007. Treatment practices and quantification of antimicrobial drug usage in conventional and organic dairy farms in Wisconsin. J. Dairy Sci. 90:249-261.

Regula, G., J. Danuser, B. Spycher, and B. Wechsler. 2004. Health and welfare of dairy cows in different husbandry systems in Switzerland. Prev. Vet. Med. 66:247-264.

Richert, R. M., K. M. Cicconi, M. J. Gamroth, Y. H. Schukken, K. E. Stiglbauer, and P. L. Ruegg. 2013. The role of the veterinarian on organic and conventional dairy farms. J. Am. Vet. Med. Assoc. 242:1732-1743.

Rouha-Mülleder, C., C. Iben, E. Wagner, G. Laaha, J. Troxler, and S. Waiblinger. 2009. Relative importance of factors influencing the prevalence of lameness in Austrian cubicle loose-housed dairy cows. Prev. Vet. Med. 92:123-133.

Ruegg, P. L. 2009. Management of mastitis on organic and conventional dairy farms. J. Anim. Sci. 87:43-55. 
Rutherford, K. M. D., F. M. Langford, M. C. Jack, L. Sherwood, A. B. Lawrence, and M. J. Haskell. 2009. Lameness prevalence and risk factors in organic and non-organic dairy herds in the United Kingdom. Vet. J. 180:95-105.

SAS Institute. 2011. SAS/STAT User's Guide. Version 9.3. SAS Institute Inc., Cary, NC.

Sato, K., P. C. Bartlett, R. J. Erskine, and J. B. Kaneene. 2005. A comparison of production and management between Wisconsin organic and conventional dairy herds. Livest. Prod. Sci. 93:105-115.

Somers, J. G. C. J., K. Frankena, E. N. Noordhuizen-Stassen, and J. H. M. Metz. 2003. Prevalence of claw disorders in Dutch dairy cows exposed to several floor systems. J. Dairy Sci. 86:2082-2093.

Sprecher, D. J., D. E. Hostetler, and J. B. Kaneene. 1997. A lameness scoring system that uses posture and gait to predict dairy cattle reproductive performance. Theriogenology 47:1179-1187.

Stiglbauer, K. E., K. M. Cicconi, R. Richert, Y. H. Schukken, P. L. Ruegg, and M. Gamroth. 2013. Assessment of herd management on organic and conventional dairy farms in the United States. J Dairy Sci. 96:1290-1300.

Wells, S. J., A. M. Trent, W. E. Marsh, and R. A. Robinson. 1993. Prevalence and severity of lameness in lactating dairy cows in a sample of Minnesota and Wisconsin herds. J. Am. Vet. Med. Assoc. $202: 78-82$.

Whay, H. R., D. C. J. Main, A. J. F. Webster, and L. E. Green. 2003. Assessment of the welfare of dairy cattle using animal-based measurements: direct observations and investigation of farm records. Vet. Rec. 153:197-202.

Zwald, A. G., P. L. Ruegg, J. B. Kaneene, L. D. Warnick, S. J. Wells, C. Fossler, and L. W. Halbert. 2004. Management practices and reported antimicrobial usage on conventional and organic dairy farms. J. Dairy Sci. 87:191-201. 